\title{
A reference consensus genetic map for molecular markers and economically important traits in faba bean (Vicia faba L.)
}

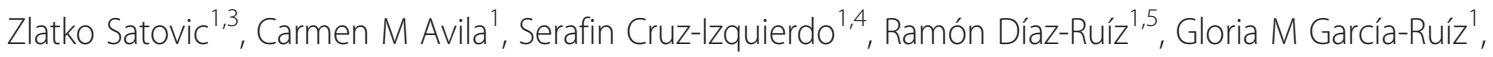
Carmen Palomino ${ }^{1}$, Natalia Gutiérrez ${ }^{1}$, Stefania Vitale ${ }^{1}$, Sara Ocaña-Moral ${ }^{1}$, María Victoria Gutiérrez ${ }^{1}$, José I Cubero ${ }^{2}$ and Ana M Torres ${ }^{1 *}$

\begin{abstract}
Background: Faba bean (Vicia faba L.) is among the earliest domesticated crops from the Near East. Today this legume is a key protein feed and food worldwide and continues to serve an important role in culinary traditions throughout Middle East, Mediterranean region, China and Ethiopia. Adapted to a wide range of soil types, the main faba bean breeding objectives are to improve yield, resistance to biotic and abiotic stresses, seed quality and other agronomic traits. Genomic approaches aimed at enhancing faba bean breeding programs require high-quality genetic linkage maps to facilitate quantitative trait locus analysis and gene tagging for use in a marker-assisted selection. The objective of this study was to construct a reference consensus map in faba bean by joining the information from the most relevant maps reported so far in this crop.
\end{abstract}

Results: A combination of two approaches, increasing the number of anchor loci in diverse mapping populations and joining the corresponding genetic maps, was used to develop a reference consensus map in faba bean. The map was constructed from three main recombinant inbreed populations derived from four parental lines, incorporates 729 markers and is based on 69 common loci. It spans 4,602 cM with a range from 323 to 1041 loci in six main linkage groups or chromosomes, and an average marker density of one locus every $6 \mathrm{cM}$. Locus order is generally well maintained between the consensus map and the individual maps.

Conclusion: We have constructed a reliable and fairly dense consensus genetic linkage map that will serve as a basis for genomic approaches in faba bean research and breeding. The core map contains a larger number of markers than any previous individual map, covers existing gaps and achieves a wider coverage of the large faba bean genome as a whole. This tool can be used as a reference resource for studies in different genetic backgrounds, and provides a framework for transferring genetic information when using different marker technologies. Combined with syntenic approaches, the consensus map will increase marker density in selected genomic regions and will be useful for future faba bean molecular breeding applications.

Keywords: Faba bean, Consensus map, Gene based markers, Quantitative trait loci, Comparative mapping, Molecular breeding, Marker-assisted selection, Genomics

\footnotetext{
* Correspondence: anam.torres.romero@juntadeandalucia.es

${ }^{1}$ IFAPA, Centro Alameda del Obispo, Área de Mejora y Biotecnología, Avda.

Menéndez Pidal s/n, Apdo. 3092, Córdoba 14080, Spain

Full list of author information is available at the end of the article
} reproduction in any medium, provided the original work is properly cited. The Creative Commons Public Domain Dedication waiver (http://creativecommons.org/publicdomain/zero/1.0/) applies to the data made available in this article, unless otherwise stated. 


\section{Background}

Faba bean (Vicia faba L.) is an important food and fodder crop worldwide and a staple in Middle East, Central and East Asia and North Africa. In terms of cultivation area, faba bean ranks fourth among the cool-season food legumes (close to 2.5 million hectares per year) after chickpea, pea and lentil (http://faostat.fao.org). Its agricultural role is currently increasing as the crop is receiving a renovated interest in European countries, North America and Australia.

Faba bean is a diploid legume crop $(2 n=2 \times=12)$ with facultative cross-pollination and has one of the largest described genomes among legumes. The genome size is $\sim 13,000 \mathrm{Mb}$, more than 25 times larger than that of the model Medicago truncatula, and contains more than $85 \%$ of repetitive DNA [1]. The large chromosome size has allowed faba bean to become one of the cytogenetically best characterised plant species. However, it has also difficulted the development of saturated linkage maps and the identification of relevant genes/QTLs (Quantitative Trait Loci). Moreover, it precludes wholegenome shotgun assembly with next generation sequencing technologies.

Genetic linkage maps are essential tools for a wide range of genetic and breeding applications, including the study of inheritance of qualitative and quantitative traits and the identification of markers linked to relevant agronomic traits. The availability of high-density maps enhances the breeding process through the application of association analyses, map-based cloning or markerassisted approaches. Table 1 presents a summary of the faba bean linkage maps reported so far.

Prior to 1990, only a few morphological and isozyme loci were mapped in the $V$. faba genome and no extended linkage groups (LGs) had been reported. Primary trisomics and translocation stocks allowed the first assignment of genes and LGs to specific chromosomes [3,16-19]. This approach was further explored to develop physically localized markers and microsatellites (or SSRSimple Sequence Repeats) from specific chromosomic regions [20]. This led to the integration of the first genetic and physical maps and allowed the unambiguous assignation of LGs to their respective chromosomes.

Preliminary maps constructed with $\mathrm{F}_{2}$ populations were mostly based on dominant markers such as RAPDs together with morphological, isozyme, seed storage protein genes and microsatellites, which saturated different areas of the genome [5-8,21,22]. First attempts to map genes/ QTLs for seed weight [6] and resistance to a parasitic plant (Orobanche crenata) and fungal diseases (Ascochyta

Table 1 Information of relevant faba bean mapping populations highlighting the ones used to construct this composite map

\begin{tabular}{|c|c|c|c|c|c|c|c|}
\hline Reference & Cross & Mapping population & No. individuals & No. markers & No. LGs ${ }^{a}$ & Length (cM) & Uses $^{\mathrm{b}}$ \\
\hline Van de Ven et al. [2] & & $B C$ & & 17 & $7(-)$ & 231 & \\
\hline Torres et al. [3] & & $2 \mathrm{~F}_{2}$ & 20 & 51 & $11(1)$ & $\sim 300$ & \\
\hline Ramsay et al. [4] & & $\mathrm{BC}$ & & 23 & $7(-)$ & $\sim 300$ & \\
\hline Satovic et al. [5] & c & $7 F_{2}$ & 813 & 157 & $48(6)$ & $\sim 850$ & $\mathrm{~T} / \mathrm{C}$ \\
\hline Vaz Patto et al. [6] & Vf6 × Vf27 & $3 F_{2}$ & 175 & 116 & $13(7)$ & $\sim 1200$ & $\mathrm{~T} / \mathrm{C}$ \\
\hline Román et al. [7,8] & Vf6 $\times$ Vf136 & $\mathrm{F}_{2}$ & 196 & 121 & $16(9)$ & 1446 & Q \\
\hline Román et al. [9] & $d$ & $11 F_{2}$ & 654 & 192 & $14(5)$ & 1559 & $\mathrm{~T} / \mathrm{C}$ \\
\hline Ávila et al. [10] & $29 \mathrm{H} \times \mathrm{Vf1} 36$ & $\mathrm{~F}_{2}$ & 159 & 103 & $18(6)$ & 1308 & Q \\
\hline Ellwood et al. [11] & $V f 6 \times V f 27$ & RIL & 96 & 135 & $12(-)$ & 1686 & \\
\hline Arbaoui et al. [12] & Côte d'Or×BPL14628 & RIL & 101 & 131 & $21(-)$ & $\sim 980$ & Q \\
\hline Díaz et al. $[17,19]$ & Vf6 $\times$ Vf136 & RIL & 165 & 277 & $21(9)$ & 2857 & Q \\
\hline Cruz-Izquierdo et al. [13] & $V f 6 \times V f 27$ & RIL & 124 & 258 & $16(8)$ & 1874 & Q \\
\hline Ma et al. [14] & $91825 \times \mathrm{K} 1563$ & $\mathrm{~F}_{2}$ & 129 & 128 & $15(-)$ & 1587 & \\
\hline Gutiérrez et al. (in press) [15] & $29 \mathrm{H} \times \mathrm{Vf136}$ & RIL & 119 & 171 & $29(15)$ & 1402 & Q \\
\hline \multirow[t]{2}{*}{ This study } & e & 3 RIL & 408 & $587^{f}$ & $6(6)$ & 3515 & $\mathrm{C}$ \\
\hline & & & & $151^{9}$ & $37(7)$ & 1171 & C \\
\hline
\end{tabular}

${ }^{a}$ Between brackets no. of linkage groups (LGs) assigned to chromosomes.

${ }^{\mathrm{b}} \mathrm{T}$ : Assignation of linkage groups to chromosomes by trisomic segregation; C: Development of a composite map; Q: QTL analysis.

'Vf6 $\times$ Vf2; Vf6 $\times$ Vf33; Vf6 $\times$ Vf159.

${ }^{d} \mathrm{Vf6} \times \mathrm{Vf2} ; \mathrm{Vf6} \times \mathrm{Vf27}$ Vf6 $\times$ Vf33; Vf6 $\times$ Vf136; Vf6 $\times$ Vf159.

${ }^{\mathrm{e}} \mathrm{Vf6} \times \mathrm{Vf27}$; Vf6 $\times \mathrm{Vf136} ; 29 \mathrm{H} \times \mathrm{Vf136}$.

fData of the six main LGs adscribed to chromosomes.

${ }^{9}$ Data of the minor LGs.

Studies carried out by the IFAPA group and considered in this study in bold. 
fabae and Uromyces viciae-fabae) were reported [7,8,10,23]. Using a $F_{2}$ population from the cross Vf6 $\times$ Vf136, a linkage map was developed to locate QTLs controlling crenate broomrape (O. crenata) [7] and $A$. fabae resistance [8]. Nine of the 16 LGs reported could be assigned to specific chromosomes thanks to markers that were common with those of previous studies. Subsequently, a linkage map of an $\mathrm{F}_{2}$ population from the cross $29 \mathrm{H} \times$ Vf136, segregating for resistance to the two pathogens, was constructed in which 6 of the 18 LGs were assigned to chromosomes [10].

These faba bean maps did not allow wider mapping comparisons, since they mostly shared dominant and anonymous markers such as RAPDs, with scarce transferrability between genotypes and legume species. Despite this limitation, marker data of $11 \mathrm{~F}_{2}$ populations (Table 1 ), all sharing the common female parent Vf6, were used to construct a composite linkage map [9]. After joint segregation analysis of 501 markers in 654 individuals, 192 markers were included in 14 major LGs, of which 5 were unambiguously assigned to specific chromosomes (Table 1). This composite map covered 1,559 cM and was one of the most comprehensive faba bean genetic map published to date [9].

These maps with dominant markers in $\mathrm{F}_{2}$ were followed by more precise maps constructed in the corresponding RIL populations, using co-dominant markers. In addition to microsatellites, expressed sequence tags (EST) from other legume species emerged as efficient tools in faba bean. A large number of intron-targeted primer pairs (ITAPs), developed within the Grain Legumes Integrated Project-GLIP (http://www.pcgin.org/GLIP/pubrep.pdf), was tested and mapped in two faba bean inbred populations (Vf6 $\times$ Vf136, 29H $\times$ Vf136). These were used to validate QTLs underlying broomrape and Ascochyta resistance in different environments and genetic backgrounds [15,24-26]. A third RIL population derived from cross $\mathrm{Vf} 6 \times \mathrm{Vf} 27$ was used to construct the first exclusively gene-based genetic map in faba bean. It contained 135 ITAPs joined in 12 unassigned LGs, that spanned 1,685 cM, and allowed for the first time the study of macrosyntenic relationships between $V$. faba, M. truncatula, Lens culinaris and other legume species [11]. After further saturation, the map was used to identify and validate QTLs controlling flowering time and other yield-related traits [13]. Recently, a new map was reported based on the $F_{2}$ population from the cross $91825 \times \mathrm{K} 1563$, which includes 128 SSRs markers arranged in 15 unassigned LGs [14]. Unfortunately the lack of common markers prevented comparisons with previous mapping studies.

To date 14 major genetic maps have been constructed in faba bean (Table 1). Integrating the information of multiple populations from diverse genetic backgrounds offers several advantages over individual genetic maps: (i) a larger number of loci is mapped than in single crosses, (ii) the relative position of common markers can be determined across the mapping populations, (iii) better genome coverage and opportunities to validate marker order, (iv) better assignment of LGs to chromosomes, (v) it allows comparison of genes/QTLs of interest across maps and, (vi) it provides the basis for comparing genomes between related species [27-29]. Consensus genetic maps have been developed in many crops such as wheat [30], maize [31], barley [32] and rice [33], and in the legume crops soybean [34], pea [35], chickpea [36], phaseolus [37], pigeonpea [38], cowpea [39], groundnut [40] and red clover [41].

With the development of genome sequencing projects and expression studies in different model and crop legumes, the construction of a faba bean consensus genetic map has become possible. The objectives of this study were to: (1) saturate the faba bean maps developed in RIL progenies with common gene based markers to facilitate anchoring of linkage groups from different populations, (2) update the position of the most relevant faba bean QTLs controlling resistance and yield related traits using Bulked Segregant Analysis (BSA), and (3) construct a reference map integrating all the genomic information reported so far in this crop. To this aim, we fused information of $11 \mathrm{~F}_{2}$ populations and marker data of three RIL genetic maps to derive a consensus map including 729 markers and covering 4,602 cM. The six main LGs could be unambiguously assigned to their corresponding faba bean chromosomes. The map represents a significant improvement over single-population genetic maps and provides a new tool of reference for faba bean breeding and genomic approaches.

\section{Results \\ Individual maps and QTL analysis Cross Vf6 $\times$ Vf27 (RIL1)}

The first RIL1 map [13] included 258 markers joined in 16 LGs and covering 1,875 cM. The linkage groups were composed of 2-45 loci with an average marker interval of $7.3 \mathrm{cM}$. The map allowed to identify and validate QTLs controlling 5 flowering and reproductive traits [13]: days to flowering (DF), flowering length (FL), pod length (PL), number of seeds per pod (NSP) and number of ovules per pod (NOP), located mainly in chromosomes (chr.) V and VI (Additional file 1: Table S1).

For the extended RIL1 map constructed herein, 313 polymophic markers were used in the global analysis (Table 2). Of these, 273 were assembled in 19 LGs, 11 of which could be assigned to specific chromosomes. The distance covered by the map was $2,183 \mathrm{cM}$ with an average marker interval of $10 \mathrm{cM}$. Sixty five of the markers are common with the other two RIL populations, 25 
Table 2 Number and type of markers genotyped in each inbred population

\begin{tabular}{lccc}
\hline Type of marker & \multicolumn{3}{c}{ RIL population } \\
\cline { 2 - 4 } & $\mathbf{V f 6 \times \mathbf { V f 2 7 }}$ & $\mathbf{V f 6} \times \mathbf{V f 1 3 6}$ & $\mathbf{2 9 H} \times \mathbf{V f 1 3 6}$ \\
\hline ITAP & 176 & 59 & 46 \\
RAPD & 107 & 327 & 145 \\
SSR & 16 & 6 & 6 \\
IsOzyme & 5 & 4 & 0 \\
RGA & 4 & 5 & 5 \\
Morphological trait & 2 & 0 & 0 \\
Seed storage protein & 2 & 2 & 2 \\
DR & 1 & 1 & 1 \\
Total & 313 & 404 & 205 \\
\hline
\end{tabular}

with RIL2 (Vf6 $\times$ Vf136) only, 15 with RIL3 $(29 \mathrm{H} \times$ Vf136) only and 25 with both (Table 3).

\section{Cross VF6 $\times$ VF136 (RIL2)}

The previously published RIL2 map [24,25] was based on 277 marker loci assembled in 21 LGs (16 consisting of 3 or more markers) that span 2,857 cM with an average marker interval of $12.7 \mathrm{cM}$. In this population, 2 QTLs controlling ascochyta blight resistance ( $A f 1$ and Af2) were identified on chr. III and chr. II [24]. In parallel studies, 2 QTLs (Of1 and Of2) controlling O. foetida resistance and 4r QTLs controlling O. crenata resistance $(O c 2-O c 5)$ were detected [25]. Oc2 and Oc3 were stable in at least two of the three environments, while Oc4 and Oc5 were only detected in one environment and thus appeared to be environment-dependent.

In an attempt to saturate the regions bearing the $O$. crenata and A. fabae QTLs, a BSA approach based on RAPD markers was applied. Two-hundred and eight of the 748 RAPD primers assayed in the cross revealed promising polymorphisms between at least one pair of bulks and were subsequently used to screen 14 plants individually. Only 41 of the RAPD primers maintained the expected pattern of polymorphism and were used to screen the entire RIL2 population, resolving 39 scorable polymorphic markers. Of these, 31 markers exhibited the expected segregation pattern and were thus included in the RIL data set for mapping and QTL analysis. Thirty of the 31 RAPD markers were mapped, 24 to target regions [11 to chr. VI $(O c 2), 8$ to chr. II (Oc3 and $A f 2)$ and 5 to chr. III (Af1)] and 6 to other LGs (Table 4; Figure 1). To increase the number of common markers between different faba bean crosses, additional ITAP markers were scored and the map was reconstructed using 404 segregating loci.

The map obtained in this study consists of 364 mapped loci assembled into 21 LGs, of which 13 were assigned to specific chromosomes. The genome distance covered by the map is $3,537 \mathrm{cM}$, with an average density of one marker locus every $12.6 \mathrm{cM}$ (Table 4). Fifty four markers included in RIL2 are common with the other two populations, 25 with RIL1 only, 4 with RIL3 only and 25 with both (Table 3).

As mentioned above, QTLs Oc2 and Oc3, that confer broomrape resistance, were previously validated in 2 of the 3 field trials assayed [26]. By saturating the target regions we were able to identify significant QTLs in each trial. Thus, the conservation of QTLs both across generations and environments was confirmed. In case of $O c 2$ (Additional file 1: Table S1B) a newly added marker,

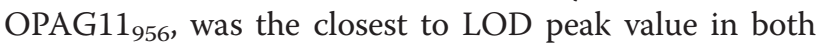
Córdoba 2003 and Córdoba 2004 datasets. Three additional QTLs were identified in chr. II (Oc14_C3 and Oc15_M4) and V (Oc15_C4). None of these QTLs was stable in the different field assays or years, pointing towards an environment-dependent expression. In the case of ascochyta blight resistance, the analysis which was based on a more saturated map yielded higher LOD scores and narrower confidence intervals for both QTLs ( $A f 1$ and $A f 2$ ). The new marker $\mathrm{OPZO}_{530}$ was the closest to LOD peak value of both Af1 QTLs identified in leaves and stems (Additional file 1: Table S1B). Addition of new markers in target areas of the map was an efficient method to increase the genome coverage and to obtain more defined QTLs.

\section{Cross $29 H \times$ VF136 (RIL3)}

The third map used in the present study was reported recently and includes 172 markers spanning $1402 \mathrm{cM}$ [15]. The linkage groups were composed of 2 to 25 loci with a marker interval of $9.87 \mathrm{cM}$. Seven QTLs for $O$. crenata (Oc7 to Oc13) and 3 QTLs for O. foetida (Of3 to $O f 5)$ were identified in this map. Oc7 was detected along three years, explaining between $22 \%$ and $33 \%$ of the phenotypic variation. It has been suggested that $O c 2$ (previously reported in RIL2) and $O c 7$, which are both located in chr. VI and validated in different environments and genetic backgrounds, might correspond to the same QTL region (Figure 1; Additional file 1: Table S1). The new analysis considered 205 marker loci segregating in this population, of which 25 were common to both other RIL populations, 25 to RIL1 only and 4 to RIL3 only (Table 3 ).

\section{Consensus linkage map}

Three sets of faba bean mapping data were used in the construction of a consensus map connecting information of $11 \mathrm{~F}_{2}$ populations, marker data of 3 RILs, as well as new markers genotyped in the present study (Tables 1 and 2). The number of individual marker loci ranged from 313 in RIL1 to 404 in RIL2 and 205 in RIL3 
Table 3 Common markers used as anchors for map integration

\begin{tabular}{|c|c|c|c|c|c|}
\hline \multirow{2}{*}{ No. } & \multirow{2}{*}{ Marker } & \multirow{2}{*}{ Marker type } & \multicolumn{3}{|c|}{ RIL population } \\
\hline & & & Vf6 $\times$ Vf27 & Vf6 $\times$ Vf136 & $29 H \times V f 136$ \\
\hline 1 & PeaßGlu & $\mathrm{DR}$ & $x$ & $x$ & \\
\hline 2 & $\operatorname{Prx}-1$ & Isozyme & $x$ & $x$ & \\
\hline 3 & Sod-1 & Isozyme & $x$ & $x$ & \\
\hline 4 & $1433 P$ & ITAP & $x$ & & $x$ \\
\hline 5 & $6 \mathrm{DCS}$ & ITAP & $x$ & $x$ & $x$ \\
\hline 6 & $\mathrm{AlGPb}$ & ITAP & $x$ & $x$ & \\
\hline 7 & AnMtS13 & ITAP & $x$ & $x$ & $x$ \\
\hline 8 & AnMtS37 & ITAP & $x$ & $x$ & \\
\hline 9 & BGAL & ITAP & $x$ & & $x$ \\
\hline 10 & cgP137F & ITAP & $x$ & & $x$ \\
\hline 11 & GBNP & ITAP & $x$ & & $x$ \\
\hline 12 & GLIP171b & ITAP & $x$ & $x$ & \\
\hline 13 & GLIP651 & ITAP & $x$ & $x$ & \\
\hline 14 & $\mathrm{HBP} 2$ & ITAP & $x$ & & $x$ \\
\hline 15 & LG007 & ITAP & $x$ & & $x$ \\
\hline 16 & LG031 & ITAP & $x$ & $x$ & $x$ \\
\hline 17 & LG041 & ITAP & $x$ & $x$ & \\
\hline 18 & LG054 & ITAP & $x$ & $x$ & \\
\hline 19 & LG068 & ITAP & $x$ & $x$ & $x$ \\
\hline 20 & Lup066 & ITAP & $x$ & $x$ & $x$ \\
\hline 21 & Lup299 & ITAP & $x$ & $x$ & $x$ \\
\hline 22 & MMK1a & ITAP & $x$ & & $x$ \\
\hline 23 & mtmt_GEN_00012_03_1 & ITAP & $x$ & $x$ & $x$ \\
\hline 24 & mtmt_GEN_00022_02_1 & ITAP & & $x$ & $x$ \\
\hline 25 & mtmt_GEN_00024_04_1 & ITAP & $x$ & $x$ & \\
\hline 26 & mtmt_GEN_00032_01_1/a & ITAP & $x$ & $x$ & \\
\hline 27 & mtmt_GEN_00036_02_1/a & ITAP & $x$ & $x$ & $x$ \\
\hline 28 & mtmt_GEN_00103_01_1 & ITAP & $x$ & $x$ & \\
\hline 29 & mtmt_GEN_00447_04_3 & ITAP & $x$ & & $x$ \\
\hline 30 & mtmt_GEN_00477_04_1 & ITAP & $x$ & & $x$ \\
\hline 31 & mtmt_GEN_00510_01_1 & ITAP & $x$ & & $x$ \\
\hline 32 & mtmt_GEN_00757_03_1 & ITAP & $x$ & $x$ & $x$ \\
\hline 33 & mtmt_GEN_00861_03_1 & ITAP & $x$ & & $x$ \\
\hline 34 & mtmt_GEN_00866_02_1 & ITAP & & $x$ & $x$ \\
\hline 35 & mtmt_GEN_00892_01_3 & ITAP & $x$ & $x$ & $x$ \\
\hline 36 & mtmt_GEN_00995_01_1 & ITAP & $x$ & $x$ & $x$ \\
\hline 37 & mtmt_GEN_01017_03_3 & ITAP & $x$ & $x$ & \\
\hline 38 & mtmt_GEN_01102_02_1 & ITAP & $x$ & $x$ & $x$ \\
\hline 39 & mtmt_GEN_01109_01_1 & ITAP & $x$ & $x$ & $x$ \\
\hline 40 & mtmt_GEN_01115_02_1 & ITAP & $x$ & & $x$ \\
\hline 41 & mtmt_GEN_01130_02_1 & ITAP & $x$ & $x$ & $x$ \\
\hline 42 & mtmt_GEN_01951_11_1a & ITAP & $x$ & $x$ & $x$ \\
\hline 43 & Pis_GEN_14_7_1 & ITAP & & $x$ & $x$ \\
\hline
\end{tabular}


Table 3 Common markers used as anchors for map integration (Continued)

\begin{tabular}{|c|c|c|c|c|c|}
\hline 44 & Pis_GEN_20_1_1 & ITAP & $x$ & $x$ & \\
\hline 45 & Pis_GEN_23_5_6_1 & ITAP & $x$ & $x$ & \\
\hline 46 & Pis_GEN_25_2_3_1 & ITAP & $x$ & $x$ & \\
\hline 47 & Pis_GEN_5_4_5_1 & ITAP & $x$ & $x$ & \\
\hline 48 & Pis_GEN_57_1_2_1 & ITAP & $x$ & $x$ & \\
\hline 49 & Pis_GEN_6_3_1 & ITAP & $x$ & $x$ & $x$ \\
\hline 50 & Pis_GEN_7_1_2_1 & ITAP & $x$ & $x$ & \\
\hline 51 & psat_EST_00180_01_2 & ITAP & $x$ & $x$ & \\
\hline 52 & psat_EST_00190_01_1 & ITAP & $x$ & & $\mathrm{x}$ \\
\hline 53 & PsMnSOD & ITAP & & $x$ & $x$ \\
\hline 54 & psmt_EST_00196_01_1 & ITAP & $x$ & $x$ & \\
\hline 55 & RBPC/O & ITAP & $x$ & & $\mathrm{x}$ \\
\hline 56 & RNAR & ITAP & $x$ & & $x$ \\
\hline 57 & SAT & ITAP & $x$ & $x$ & \\
\hline 58 & TBB2 & ITAP & $x$ & $x$ & $\mathrm{x}$ \\
\hline 59 & UNK28 & ITAP & $x$ & $x$ & \\
\hline 60 & RGA01 & RGA & $x$ & $x$ & $x$ \\
\hline 61 & RGA03 & RGA & $x$ & $x$ & $x$ \\
\hline 62 & RGA08 & RGA & $x$ & $x$ & $x$ \\
\hline 63 & RGA09 & RGA & $x$ & $x$ & $x$ \\
\hline 64 & B3 & Seed storage protein & $x$ & $x$ & \\
\hline 65 & B4 & Seed storage protein & $x$ & $x$ & $\mathrm{x}$ \\
\hline 66 & GA4 & SSR & $x$ & $x$ & $\mathrm{x}$ \\
\hline 67 & GAll30 & SSR & $x$ & $x$ & \\
\hline 68 & GAll59 & SSR & $x$ & $x$ & $x$ \\
\hline \multirow[t]{2}{*}{69} & JF1GA3 & SSR & $x$ & $x$ & $x$ \\
\hline & \multicolumn{2}{|c|}{ Total number of common markers } & 65 & 54 & 44 \\
\hline
\end{tabular}

(Table 2). Chi-square test was performed on new marker genotyping data for individual mapping population,s to test the null hypothesis of segregation ratios of 1:1. A variable percentage of distorted markers $(\mathrm{P}<0.01)$ was observed, ranging from $2.93 \%$ in RIL3 to $7.35 \%$ in RIL1. A list of the marker loci is provided in Additional file 2: Table S2. QTL regions characterized in previous studies were also covered by the present consensus map.

The number of anchor markers for pairwise comparisons was initially small, with less than 20 markers in common. However, after the new marker analysis the number triplicated to 69 (2 isozymes, 4 SSRs, 2 legumines, 4 RGAs, 1 DR gene and 56 ITAPs). Sixty five of these, present in RIL1, were primarily used as bridges to integrate the individual maps into a single consensus map (Table 3). Twenty five markers were common in the 3 maps, while the remaining 44 were shared by at least 2 mapping populations. As a result, marker segregation data were assembled for a total of 828 marker loci, 759 of which were unique i.e. mapped only in one population (Table 5; Additional file 2: Table S2).

A total of 729 marker loci were assembled into the 43 LGs constituting the consensus map (Figure 1; Table 5), while 99 markers remained unlinked. The 6 major LGs contained between 53 (chr. V) and 165 marker loci (chr. I), and were assigned to the corresponding chromosomes. Seven additional LGs (Ia to IVa) could also be assigned thanks to the presence of loci previously located in individual chromosomes. Thirty one LGs consisted of 2-5 markers, and the remaining 6 LGs contained between 6 and 21 loci (Table 5; Additional file 2: Table S2). The total length of the consensus genetic linkage map was $4,613 \mathrm{cM}$, of which $3,442 \mathrm{cM}$ were covered by the 6 main LGs/chromosomes. The length of these major LGs ranged from $323 \mathrm{cM}$ (chr. V) to $1041 \mathrm{cM}$ (the large metacentric chr. I). The entire consensus map had an average marker density of one marker per $10.7 \mathrm{cM}$, which was reduced to $6 \mathrm{cM}$ when considering only the 6 
Table 4 Linkage map of Vf6 $\times$ Vf136 (RIL2)

\begin{tabular}{|c|c|c|c|c|c|}
\hline No. & $\begin{array}{c}\text { Chromosome/ } \\
\text { LG* }^{*}\end{array}$ & $\begin{array}{c}\text { No. } \\
\text { markers }\end{array}$ & $\begin{array}{c}\text { New } \\
\text { markers** }\end{array}$ & $\begin{array}{l}\text { Length } \\
\text { (cM) }\end{array}$ & $\begin{array}{c}\text { Intermarker } \\
\text { distance (cM) }\end{array}$ \\
\hline 1 & $\mid-1$ & 69 & $1 / 7$ & 730.18 & 10.74 \\
\hline 2 & $1-2$ & 15 & $2 / 2$ & 164.43 & 11.75 \\
\hline 3 & $1-3$ & 2 & $0 / 2$ & 21.18 & 21.18 \\
\hline 4 & IC & 2 & $0 / 0$ & 8.67 & 8.67 \\
\hline 5 & $\|$ & 53 & $8 / 11$ & 522.80 & 10.05 \\
\hline 6 & Ila & 11 & $0 / 1$ & 80.19 & 8.02 \\
\hline 7 & || $\mid-1$ & 53 & $5 / 12$ & 462.63 & 8.90 \\
\hline 8 & || $\mid-2$ & 4 & $0 / 1$ & 33.88 & 11.29 \\
\hline 9 & IV & 38 & $2 / 2$ & 346.53 & 9.37 \\
\hline 10 & $V-1$ & 27 & $0 / 5$ & 290.67 & 11.18 \\
\hline 11 & V-2 & 7 & $0 / 1$ & 55.24 & 9.21 \\
\hline 12 & $\mathrm{VI}-1$ & 28 & $0 / 8$ & 284.94 & 10.55 \\
\hline 13 & $\mathrm{VI}-2$ & 24 & $11 / 3$ & 228.73 & 9.94 \\
\hline 14 & LG01 & 8 & $0 / 0$ & 61.63 & 8.80 \\
\hline 15 & LG04 & 6 & $0 / 0$ & 86.05 & 17.21 \\
\hline 16 & LG05 & 5 & $1 / 0$ & 48.55 & 12.14 \\
\hline 17 & LG06 & 4 & $0 / 0$ & 37.40 & 12.47 \\
\hline 18 & LG11 & 2 & $0 / 0$ & 20.27 & 20.27 \\
\hline 19 & LG21 & 2 & $0 / 0$ & 22.14 & 22.14 \\
\hline 20 & LG22 & 2 & $0 / 2$ & 11.93 & 11.93 \\
\hline \multirow[t]{4}{*}{21} & LG23 & 2 & $0 / 0$ & 18.80 & 18.80 \\
\hline & Mapped & 364 & $30 / 57$ & 3536.86 & 12.60 \\
\hline & Unmapped & 40 & & & \\
\hline & Total & 404 & & & \\
\hline
\end{tabular}

*Linkage groups correspond to those of the composite map.

** Markers mapped in addition to already published linkage map [24,25]: first number represents the number of markers added by saturation mapping targeted at the regions conferring resistance to $O$. crenata and Ascochyta fabae (II, III-1, VI-2), while the second is the number of markers added to increase the number of common markers among different faba bean crosses.

main LGs. The marker order of the integrated map was largely collinear with the three individual maps, although a few local inversions and marker rearrangements over short intervals were observed.

\section{Integration of QTL information}

The number of QTL studies in faba bean is relatively low compared to other major legume species. Most traits have been genetically characterized in only one or two different mapping experiments, which limits the meta-analysis of QTLs in this species. Moreover, QTL intervals did not always include the minimum of two anchor markers, which is required for their projection onto the consensus map. Nevertheless, by comparing the maps published to date we provide a synthetic view of the most relevant loci controlling polygenic traits in faba bean. Further mapping of common markers between maps will be crucial to enhance the comparison of QTL positions from different mapping studies and to refine the localization of hot-spot genomic regions.

The 5 faba bean mapping experiments in the 3 RIL populations reported so far, identified 37 QTLs for 9 traits (Additional file 1: Table S1). Most of the QTL analyses focused on biotic stresses (e.g. broomrape and ascochyta blight resistance). The number of QTLs for broomrape resistance is 15 for $O$. crenata and 5 for $O$. foetida. Meanwhile the $A$. fabae resistance QTLs were reduced to 2, $A f 1$ and $A f 2$, that were conserved among populations ( $\mathrm{F}_{2}$ and RIL) and environments. Regarding flowering and yield related traits, the number of stable QTLs reported were 1 (NOP), 2 (FL), 4 (PL), 3 (NSP) and 5 (DF) (Additional file 1: Table S1). The distribution of these 37 QTLs varied from 9 in chr. I, 8 in chr. II, 4 in chr. III and VI, 3 in chr. IV, 6 in chr. V. The last three QTLs remained unassigned.

\section{Discussion}

During the last decade, significant progress was made in the development of genotyping tools. This allowed the addition of a large number of robust and transferrable marker loci in the genetic maps of relevant crop species. In faba bean, mapping studies were initiated in the 90's with the development of the first maps in $\mathrm{F}_{2}$ populations using mostly RAPDs together with SSRs, isozymes and morphological markers. Previous studies comparing these linkage maps have been reported [9]. The use of a recurrent parent (Vf6) in all the $F_{2}$ populations then allowed to join data from different progenies by means of common markers in the female parent. Moreover, the use of trisomic families for chromosomes III, IV, V and VI allowed allocation of LGs to chromosomes [9]. Ever since, attempts have been made to increase marker density using new SSRs and gene-based markers in RIL populations. The main objective of the present study was the development of a high density consensus genetic map that integrates all the relevant maps reported so far and serves as a reference map for the international faba bean community.

Building a consensus map is not possible without common or bridge loci on each LG or chromosome. For this reason, a number of additional markers was genotyped in each mapping population to increase the number of common markers among them. A bridge marker was considered as such when its name and position were the same in the different mapping populations. The genetic map was created combining two approaches: (a) increasing the number of anchor marker loci in the different populations, (b) merging the resulting genetic maps through markers common to three RIL populations with MergeMap [42] as reported in many other crop species [39,43-47]. 


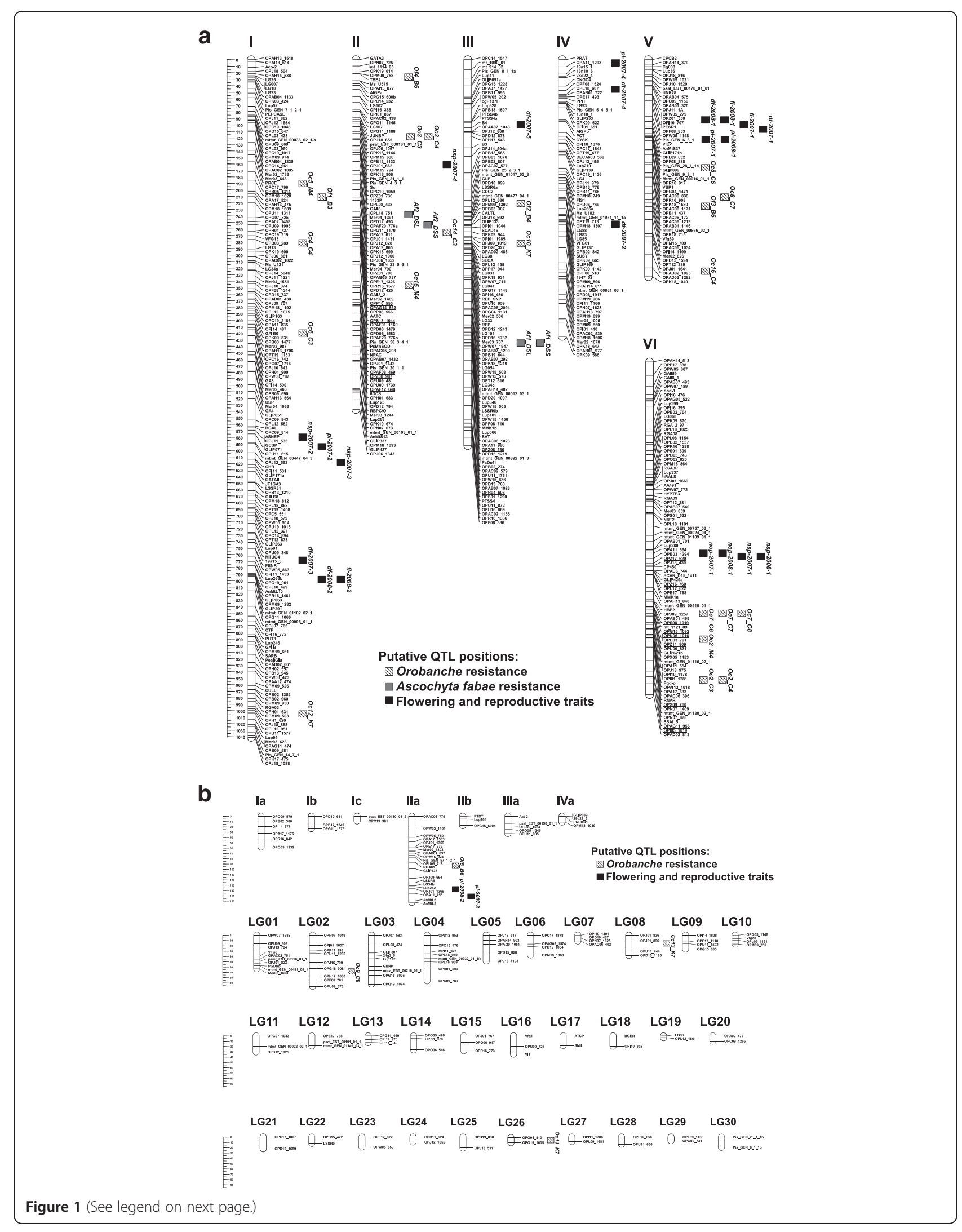


(See figure on previous page.)

Figure 1 Faba bean consensus map showing: (a) the six main linkage groups or chromosomes (578 loci) and (b) minor linkage groups (30) or small chromosome fragments (7). Additional markers derived from the BSA analysis are underlined. Boxes represent putative locations of QTLs. Black boxes were used for flowering and yield related traits: days to flowering $(d f)$, flowering length ( $f$ ), pod length ( $p /)$, number of ovules per pod (nop) and number of seeds per pod (nsp). Grey boxes: Ascochyta fabae (Af) QTLs. Stripped boxes: Orobanche crenata (Oc) and Orobanche foetida QTLs. Marker distance is given in CM.

Using this approach, segregation data for 729 marker were assembled on 43 LGs. In terms of marker order, the consensus map contains few changes compared to the individual maps. Small discrepancies in the marker order or position in some LGs might be due to (i) different population sizes used, (ii) weak linkages existing in the different maps, or (iii) missing or poor quality data, rather than to real chromosome rearrangements. As reported in previous studies in Vitis vinifera L. [47], phaseolus [37] or Brassica napus [44], the faba bean consensus marker order is significantly more reliable than that of the individual maps because of the higher number of individuals and recombination events occuring across three or more populations.

Based on previous LG/marker allocations, 13 of the larger LGs could be assigned to specific chromosomes while 30 LGs remained unassigned. Considering the enormous size of the faba bean genome, unassigned LGs may be due to recombination gaps at the distal ends of the main LGs because of a lack of marker loci. None of the main LGs differed considerably in marker density. The length of our core map was 3,431 cM, which is higher than the single RIL maps. In many other species the increased size of the composite map was attributed to an improved coverage of the chromosome ends [37,48-50].

All the individual maps reported to date allocate LGs to 5 of the 6 faba bean chromosomes, excluding chr. IV. After acknowledging the erroneous assignment of LG I. $B$, which actually corresponds to chr. IV [51], the new integrated map anchors for the first time the main LGs to the whole chromosome complement of the species. This information was used here to update the reported large-scale synteny between LGs and/or chromosomes of M. truncatula and cool season grain legumes such as pea, chickpea, lens and faba bean [52]. Figure 2 shows the main syntenic blocks and rearrangements among these species and their correspondence to the six faba bean chromosomes.

The integration of a high number of coding regions in the consensus map provides an excellent framework for downstream analyses, including comparisons between the locations of major genes for important traits or QTL positions between populations from different crosses. Moreover, combining syntenic studies with a consensus map will contribute to increase marker density in genomic regions of interest for indirect selection or for map based cloning [37]. Successful application of consensus maps for synteny based candidate gene identification and/or definition of QTL location has been extensively used both in cereals [59-62] and in legumes [35,37,63,64].

The RIL mapping populations considered in the consensus map were used previously for detecting QTLs of agronomically important traits. These are displayed in Figure 1, together with the QTLs identified in the improved Vf6 $\times$ Vf136 map and detected in the present study. In order to increase the density of loci around the OTLs for broomrape and ascochyta blight resistance, we used BSA in contrasted DNA pools. The BSA approach has been applied in numerous studies and provides a platform for high-resolution genetic analysis [65]. In the present study, 24 of 31 RAPD markers were mapped to the major linkage groups and allowed more accurate determination of QTL locations and effects. These results highlight the usefulness of BSA based on markers flanking QTLs, as an efficient tool for saturation of targeted regions, opening the possibility of future marker-assisted selection for these traits.

Faba bean has been considered a "genomic orphan" crop with a huge and complex genome and limited availability of genetic and genomic resources. At present, the situation has greatly improved thanks to the technological advances in high-throughput sequencing and genotyping, together with the access to genomic and transcriptomic tools. Genome-wide transcription profiling by deepSuperSAGE was recently used for quantifying the transcriptional changes elicited by $A$. fabae and to identify candidate resistance genes governing faba bean responses to this fungal pathogen [66]. Several genome libraries have been constructed and characterized for putative SSR sequences using the Roche 454 GS FLX Titanium Sequencing Platform [67,68]. These transcriptomic studies provide a foundation for the identification of novel regulators associated with faba bean-pathogen interactions and also a valuable source of markers for molecular breeding applications in this crop.

Translation of genomic resources from the model species $M$. truncatula or other sequenced related legume species such as chickpea, should be further exploited to raise the prospects in molecular faba bean breeding programs. The availability of large sets of conserved ESTs from model or related species constitutes a valuable source of markers that are physically associated with coding regions. These are good candidates for gene cloning or faba bean 
Table 5 Composite map of faba bean (Vicia faba L.) genome

\begin{tabular}{|c|c|c|c|c|}
\hline No. & Chromosome/LG & No. markers & Length (cM) & $\begin{array}{l}\text { Intermarker } \\
\text { distance (cM) }\end{array}$ \\
\hline 1 & I & 165 & 1041.20 & 6.35 \\
\hline 2 & $\|$ & 93 & 537.60 & 5.84 \\
\hline 3 & III & 109 & 593.14 & 5.49 \\
\hline 4 & IV & 70 & 425.20 & 6.16 \\
\hline 5 & V & 53 & 333.60 & 6.42 \\
\hline 6 & $\mathrm{Vl}$ & 88 & 511.22 & 5.88 \\
\hline 7 & la & 6 & 57.80 & 11.56 \\
\hline 8 & $\mathrm{lb}$ & 3 & 23.25 & 11.63 \\
\hline 9 & Ic & 2 & 8.67 & 8.67 \\
\hline 10 & Ila & 21 & 162.46 & 8.12 \\
\hline 11 & $11 \mathrm{~b}$ & 3 & 17.48 & 8.74 \\
\hline 12 & Illa & 5 & 32.63 & 8.16 \\
\hline 13 & IVa & 4 & 11.02 & 3.67 \\
\hline 14 & LG01 & 10 & 63.25 & 7.03 \\
\hline 15 & LG02 & 9 & 96.45 & 12.06 \\
\hline 16 & LG03 & 9 & 91.99 & 11.50 \\
\hline 17 & LG04 & 8 & 86.04 & 12.29 \\
\hline 18 & LG05 & 5 & 48.55 & 12.14 \\
\hline 19 & LG06 & 4 & 37.40 & 12.47 \\
\hline 20 & LG07 & 4 & 11.07 & 3.69 \\
\hline 21 & LG08 & 4 & 37.86 & 12.62 \\
\hline 22 & LG09 & 4 & 25.98 & 8.66 \\
\hline 23 & LG10 & 4 & 16.75 & 5.58 \\
\hline 24 & LG11 & 3 & 30.36 & 15.18 \\
\hline 25 & LG12 & 3 & 18.75 & 9.38 \\
\hline 26 & LG13 & 3 & 12.63 & 6.31 \\
\hline 27 & LG14 & 3 & 26.43 & 13.22 \\
\hline 28 & LG15 & 3 & 28.03 & 14.01 \\
\hline 29 & LG16 & 3 & 34.35 & 17.18 \\
\hline 30 & LG17 & 2 & 18.24 & 18.24 \\
\hline 31 & LG18 & 2 & 19.48 & 19.48 \\
\hline 32 & LG19 & 2 & 3.48 & 3.48 \\
\hline 33 & LG20 & 2 & 9.80 & 9.80 \\
\hline 34 & LG21 & 2 & 22.14 & 22.14 \\
\hline 35 & LG22 & 2 & 11.93 & 11.93 \\
\hline 36 & LG23 & 2 & 18.80 & 18.80 \\
\hline 37 & LG24 & 2 & 9.34 & 9.34 \\
\hline 38 & LG25 & 2 & 20.67 & 20.67 \\
\hline 39 & LG26 & 2 & 9.37 & 9.37 \\
\hline 40 & LG27 & 2 & 8.41 & 8.41 \\
\hline 41 & LG28 & 2 & 13.43 & 13.43 \\
\hline 42 & LG29 & 2 & 6.89 & 6.89 \\
\hline 43 & LG30 & 2 & 19.37 & 19.37 \\
\hline
\end{tabular}

Table 5 Composite map of faba bean (Vicia faba L.) genome (Continued)

\begin{tabular}{cccc}
\hline Mapped & 729 & 4612.52 & 10.73 \\
Unmapped & 99 & & \\
Total & 828 & & \\
Main LGs (No. 1-6) & 578 & 3441.96 & 6.02 \\
\hline
\end{tabular}

marker assisted selection. This is the approach used in this study to integrate all the faba bean genomic information so far reported, and to generate a new tool of reference for faba bean breeding and genomics approaches.

\section{Conclusions}

We have constructed the first marker consensus genetic linkage map for faba bean by integrating segregation data from three recombinant inbred line populations, together with new common markers genotyped in this study. The final integrated map has allowed to (i) join a larger number of markers than in any previous individual map, (ii) obtain a more complete coverage of the faba bean genome, (iii) fill a number of gaps in previous independent maps, and (iv) improve the resolution of key QTLs. The colinearity of the consensus map was well maintained and will serve as reference for future faba bean multiple-line cross QTL mapping studies. Since $60 \%$ of the markers in the most developed map (RIL1) corresponded to coding regions, this consensus enhanced-density faba bean map provides a functional framework for candidate gene studies, expression analysis, comparative genomics, evolution studies and anchoring of the future faba bean genome sequences.

\section{Methods \\ Mapping populations}

The most recent maps of three RIL mapping populations, Vf6 $\times$ Vf27 (RIL1), Vf6 $\times$ Vf136 (RIL 2) and $29 \mathrm{H} \times \mathrm{Vf136}$ (RIL3), were used to develop an integrated map of faba bean (Table 1). Vf6 was a common female parent in two progenies, Vf6 $\times$ VF136, which segregates for broomrape and Ascochyta resistance [7,8,24-26] and Vf6 $\times$ VF27, first reported by [6] and further used to construct the first exclusively gene-based genetic map in the species [11] and to identify and validate QTLs controlling flowering time and other yield-related traits [13]. Vf136 was the common male parent with the third population, $29 \mathrm{H} \times \mathrm{Vf1} 136$, segregating for resistance to broomrape and A. fabae [10,15]. The populations consisted of 124 RILs for RIL1, 165 individual lines for RIL2, and 119 for RIL3.

The female parents, Vf6 and $29 \mathrm{H}$ are equina mediumseeded field beans with beige seed coat and resistance to A. fabae, Vf136 is also an equina type with reported resistance to broomrape and Vf27 is a black and small- 


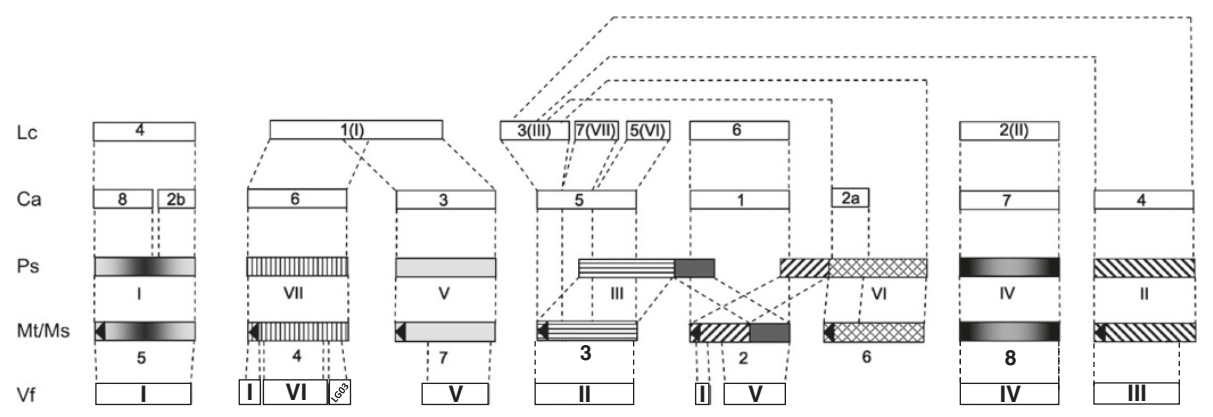

Figure 2 Schematic representation of large-scale synteny blocks between chromosomes and chromosome segments of $M$. truncatula (Mt) and main cool season grain legumes (Source [52], with modifications). Chickpea (Cicer arietinum; Ca), faba bean (Vicia faba; Vf), lens (Lens culinaris; LC), and pea (Pisum sativum; Ps). Bars representing Medicago and pea homologous chromosomal regions are shown with the same gray intensity or pattern. Arrows in the boxes indicate the orientation of the chromosomes (short arm - long arm) in the case of Medicago. The corresponding synteny blocks of faba bean, chickpea and lentil are represented by blank bars. The bars do not reflect the relative sizes of chromosome or chromosome segments and the break points of chromosomes are indicated approximately. The figure integrates data from $[11,13,53-58]$ and this study.

seeded paucijuga form, supposedly close to a putative wild faba bean progenitor [69].

\section{Marker analyses}

Genomic DNA was extracted from young leaves using liquid nitrogen and the procedure was as described by [3]. To increase marker density and to provide common markers to anchor the LGs from different populations, new markers from different sources were assayed. A set of SSRs, resistant gene analogs (RGAs), defence delated (DR) genes and ITAPs designed from different legume ESTs (M. truncatula, pea, lentil, lupin and soybean), were tested in the parental lines and the polymorphic ones genotyped in the corresponding RIL population.

\section{SSR markers}

Fifty four faba bean SSRs [70] and 41 pea SSRs [71], were assayed for polymorphism among the parental lines using their respective protocols. In case of pea SSRs the reaction mixture was modified slightly by using $2,5 \mathrm{mM}$ of $\mathrm{MgCl}_{2}$ and $1 \mathrm{U}$ Taq polymerase instead, to facilitate the orthologous amplification. SSRs revealing consistent and easily scorable bands were genotyped in the whole populations after electrophoresis in $2.5 \%-3 \%$ agarose gels.

\section{RGAs and DR genes}

Ten RGA classes were tested using PCR conditions described by [72]. To reveal polymorphism, amplification products for each RGA class were digested with a set of restriction enzymes according to the manufacturer's instructions to obtain CAPS (Cleaved Amplified Polymorphic Sequences). Twelve additional RGAs [73,74] along with 12 DR genes, cloned and mapped in different legume species and mapped in pea [74], were also assayed. Amplifications and PCR conditions were as described by [72].

Intron-targeted amplified polymorphic markers (ITAPs)

A total of 635 EST derived markers developed within the Grain Legumes Integrated Project (GLIP-Food-CT2004-506223), were tested for polymorphism among the parental lines using the amplification protocols reported by $[13,26]$. Special efforts were focused on genotyping the ITAPs previously mapped in the most advanced Vf6 $\times$ Vf27 map [11,13]. As mentioned above, when no polymorphism was detected on agarose gels, PCR products amplified from both parents were digested with a range of restriction endonucleases in order to detect a SNP as a CAPS (Cleaved Amplified Polymorphic Sequence) marker that was further genotyped in the corresponding population.

\section{Saturation mapping}

In order to saturate targeted regions conferring broomrape or ascochyta blight resistance we applied the BSA [75] based on previous QTL mapping information in cross Vf6 $\times$ Vf136 [24,26]. BSA has been widely adopted as a method to rapidly identify molecular makers in specific genome regions. The BSA principle consists in pooling DNAs from individuals from a segregating population according to two phenotypic classes. The resulting DNA bulks are equivalent to those from two Near Isogenic Lines (NILs) for which is assumed to generate a random genetic background at all other unlinked loci. In this study segregating individuals were grouped according to the genotype of markers flanking already localized QTLs. The contrasting pools were then screened with new markers in order to identify recombinants within each QTL interval.

QTLs underlying resistance to $O$. crenata and $A$. fabae were named $O c$ and $A f$, respectively [24,26]. Accordingly, 
bulks of plants fixed for alleles of the two markers flanking four QTL regions were selected from the RIL population: $\mathrm{OPNO}_{1409}$ and $\mathrm{OPAI1}_{1018}$ (flanking Oc2 on linkage group VI.B), OPC19 1059 and OPD12 425 (Oc3 on LG II.A), OPF08 $8_{710}$ and OPW15 $5_{576}$ (Af1 on chr. III), OPAG5 $_{737}$ and MER02 1469 (Af2 on chr. II). A total of 748 RAPD primers was used in search for polymorphisms between the two bulks. For a given target region, markers showing expected differences between the pair of bulks were subsequently used to screen 14 plants individually. Markers that maintained the expected pattern of polymorphisms, were then used to screen the entire RIL population.

\section{Quantitative traits}

Traits and QTL information were selected from seven published works $[7,8,10,13,15,24,26]$ and supplemented by the bulked segregant analysis (in cross VF6 $\times$ VF136) and the saturation process described above. Trait descriptions, evaluation methods and abbreviations were assigned according to the previous references. Thus, the nine traits considered (Figure 1; Additional file 2), were the following: (1) Orobanche crenata resistance (trait abbreviation OC); (2) Orobanche foetida resistance (OF); (3) Ascochyta fabae resistance: disease severity on leaves (DSL); (4) Ascochyta faba resistance: disease severity on stems (DSS); (5) Days to flowering (DF); (6) Flowering length (FL); (7) Pod length (PL); (8) Number of ovules per pod (NOP); (9) Number of seeds per pod (NSP). Most of these QTLs showed to be stable as were identified and validated in different environments or genetic background. Each QTL was treated independently, making it possible to notice the number of times that a QTL is reported in a similar genomic location across independent experiments (Figure 1; Additional file 2).

\section{Data analysis \\ Map construction and QTL analysis in Vf6 $\times$ VF136 (RIL 2)}

MAPMAKER 3.0 [76] was used to identify linkage groups using an LOD score of four as the threshold for considering significant linkage. MSTMap software [77] was used to determine maker orders by finding the minimum spanning tree of a graph for each linkage group. MAPMAKER was used to confirm marker orders determined by MSTMap and to convert the recombination fractions to centiMorgans (cM) using the mapping function of Kosambi [78].

QTL analysis was conducted using composite interval mapping (CIM) and multiple interval mapping (MIM) in Windows QTL Cartographer V2.5 [79]. Markers to be used as cofactors for CIM were selected by forwardbackward stepwise regression. The number of markers controlling the genetic background in CIM was set to five.
The thresholds for the detection of QTLs were estimated by permutations analysis [80] using 1,000 permutations.

\section{Consensus map construction}

Three individual genetic maps were used to generate a consensus map using MergeMap [42] by converting the individual maps into directed acyclic graphs (DAGs) that are then merged in consensus graph on the basis of their shared vertices [81]. As MergeMap tends to inflate genetic distances in the consensus genetic map [42,82], marker data from different mapping populations were pooled together and the order of each consensus linkage group as established by MergeMap was set, in order to calculate genetic distances using MAPMAKER. The consensus map for each linkage group was visualized by MapChart [83].

\section{Additional files}

Additional file 1: Table S1. (A) Putative QTLs for flowering time and yield related traits detected in the faba bean RIL population Vf6 $\times$ Vf27 (from Cruz-Izquierdo et al., 2012 with modifications). (B) Putative QTLs for Ascochyta fabae, Orobanche crenata and Orobanche foetida resistance detected in the faba bean RIL population Vf6 × Vf136 (Díaz-Ruíz et al., 2009a; 2009b; 2010 and this study). (C) Putative QTLs for Orobanche crenata and Orobanche foetida resistance detected in the faba bean RIL population $29 \mathrm{H} \times$ Vf136 (from Gutierrez et al., 2013 with modifications).

Additional file 2: Table S2. Information on the markers used in this study and mapped in the three faba bean RIL populations.

\section{Competing interests}

The authors declare that they have no competing interests.

\section{Authors' contributions}

ZS performed the statistical analyses for map merging, integrated QTL information, prepared tables and graphic representations and helped to draft the manuscript. CMA generated marker and QTL data for the mapping populations, participated in the design of the study and assisted with manuscript preparation and editing. SCI, RDR performed additional marker genotyping and provided new QTL data. GGR, CP, NG, SV, SOM and MVG provided new marker data for mapping saturation and anchoring points for map integration. JIC assisted with manuscript editing. AMT coordinated the map integration study, contribute to the analysis and interpretation of data, provided the marker and QTL data and drafted the manuscript. All authors read and approved the final manuscript.

\section{Acknowledgements}

This research has been funded by the Spanish projects AGL2008-02305/AGR, RTA2010-00059 and IPT-2011-1259-010000, co-financed by FEDER, and by the EU project GLIP (FP6- FOOD-CT-2004-506223). The authors thank Juan Prieto, Gloria de Lara and Ana Pozo for excellent technical assistance in the laboratory, greenhouse and field. We are grateful to A. Di Pietro for carefully reading the manuscript.

\section{Author details}

'IFAPA, Centro Alameda del Obispo, Área de Mejora y Biotecnología, Avda. Menéndez Pidal s/n, Apdo. 3092, Córdoba 14080, Spain. Departamento de Mejora Genética, IAS-CSIC, Apdo. 4084, Córdoba 14080, Spain. ${ }^{3}$ Present addresses: Department of Seed Science and Technology, Faculty of Agriculture, University of Zagreb, Zagreb, Croatia. ${ }^{4}$ Colegio de Postgraduados, Recursos Genéticos y Productividad - Genética, Campus Montecillo, Km 36.5 Carretera México-Texcoco, C.P., Texcoco, Edo. de México 56230, México.

${ }^{5}$ Colegio de Postgraduados, Campus Puebla, Km 125.5 Carretera

México-Puebla, C.P., Puebla, Pue 72760, México. 
Received: 16 September 2013 Accepted: 12 December 2013

Published: 30 December 2013

\section{References}

1. Flavell RB, Bennett MD, Smith JB, Smith DB: Genome size and proportion of repeated nucleotide sequence DNA in plants. Biochem Genet 1974, 12:257-269

2. van de Ven WTG, Waugh R, Duncan N, Ramsay G, Dow N, Powell W: Development of a genetic linkage map in Vicia faba using molecular and biochemical techniques. Aspects App/ Biol 1991, 27:49-54.

3. Torres AM, Weeden NF, Martín A: Linkage among isozyme, RFLP and RAPD markers in Vicia faba. Theor Appl Genet 1993, 85:937-945.

4. Ramsay G, van de Ven W, Waugh R, Griffiths DW, Powel W: Mapping quantitative trait loci in faba beans. In Improving production and utilisation of grain legumes. Edited by AEP. Copenhagen, Denmark: 2nd European Conference on Grain Legumes; 1995:444-445.

5. Satovic Z, Torres AM, Cubero Jl: Genetic mapping of new morphological, isozyme and RAPD markers in Vicia faba L. using trisomics. Theor Appl Genet 1996, 93:1130-1138.

6. Vaz Patto MC, Torres AM, Koblizkova A, Macas J, Cubero Jl: Development of a genetic composite map of Vicia faba using $F_{2}$ populations derived from trisomic plants. Theor App/ Genet 1999, 98:736-743.

7. Román B, Torres AM, Rubiales D, Cubero Il, Satovic Z: Mapping of quantitative trait loci controlling broomrape (Orobanche crenata Forsk.) resistance in faba bean (Vicia faba L.). Genome 2002, 45:1057-1063.

8. Román B, Satovic Z, Avila CM, Rubiales D, Moreno MT, Torres AM: Locating genes associated with Ascochyta fabae resistance in Vicia faba L. Aust $J$ Agric Res 2003, 54:85-90.

9. Román B, Satovic Z, Pozarkova D, Macas J, Dolezel J, Cubero Jl, Torres AM: Development of a composite map in Vicia faba L. breeding applications and future prospects. Theor Appl Genet 2004, 108:1079-1088.

10. Avila CM, Satovic Z, Sillero JC, Rubiales D, Moreno MT, Torres AM: Isolate and organ-specific QTLs for ascochyta blight resistance in faba bean. Theor Appl Genet 2004, 108:1071-1078.

11. Ellwood SR, Phan HTT, Jordan M, Torres AM, Avila CM, Cruz-Izquierdo S, Oliver RP: Construction of a comparative genetic map in faba bean (Vicia faba L.); conservation of genome structure with Lens culinaris. BMC Genomics 2008, 9:380.

12. Arbaoui M, Link W, Satovic Z, Torres AM: Quantitative trait loci of frost tolerance and physiologically related traits in faba bean (Vicia faba L.). Euphytica 2008, 164:93-104.

13. Cruz-Izquierdo S, Avila CM, Satovic Z, Palomino C, Gutierrez N, Ellwood SR Phan HTT, Cubero Jl, Torres AM: Comparative genomics to bridge Vicia faba with model and closely-related legume species: stability of QTLs for flowering and yield-related traits. Theor Appl Genet 2012, 125:1767-1782.

14. Ma Y, Bao S, Yang T, Hu J, Guan J, He Y, Wang X, Wan Y, Sun X, Jiang J, Gong C, Zong X: Genetic linkage map of Chinese native variety faba bean (Vicia faba L.) based on simple sequence repeat markers. Plant Breeding 2013. doi:10.1111/pbr.12074.

15. Gutiérrez N, Palomino C, Satovic Z, Ruiz-Rodríguez MD, Vitale S, Gutiérrez MV, Rubiales D, Kharrat M, Amri M, Emeran A, Cubero Il, Atienza SG, Torres AM, Avila CM: QTLs for Orobanche spp. resistance in faba bean: Identification and validation across different environments. Molecular Breeding 2013. in press

16. Cabrera A, Cubero Jl, Martín A: Genetic mapping using trisomics in Vicia faba L. FABIS Newslett 1989, 23:5-7.

17. Macas J, Dolezel J, Lucretti S, Pich U, Meister A, Fuchs J, Schubert I: Localization of seed genes on flow-sorted field bean chromosomes. Chromosome Res 1993, 1:107-115.

18. Macas J, Weschke W, Baumlein H, Pich U, Houben A, Wobus U, Schubert I: Localization of vicilin genes via polymerase chain reaction on microisolated field bean chromosomes. Plant J 1993, 3:883-886.

19. Fuchs J, Pich U, Meister A, Schubert I: Differentiation of field bean heterochromatin by in situ hybridization with a repeated Fokl sequence. Chromosome Res 1994, 2:25-28.

20. Pozarkova D, Koblizkova A, Román B, Torres AM, Lucretti S, Lysak M, Dolezel J, Macas J: Development and characterization of microsatellite markers from chromosome 1-specific DNA libraries of Vicia faba. Biol Plantarum 2002, 45:337-345.
21. Torres AM, Satovic Z, Cánovas J, Cobos S, Cubero Jl: Genetics and mapping of new isozyme loci in Vicia faba L. using trisomics. Theor App/ Genet 1995, 91:783-789.

22. Torres AM, Vaz Patto MC, Satovic Z, Cubero Jl: New isozyme loci in Faba bean (Vicia faba L.): Genetic analysis and mapping using trisomics. $J$ Hered 1998, 89:271-274.

23. Avila CM, Sillero JC, Rubiales D, Moreno MT, Torres AM: Identification of RAPD markers linked to Uvf-1 gene conferring hypersensitive resistance against rust (Uromyces viciae-fabae) in Vicia faba L. Theor Appl Genet 2003, 107:353-358.

24. Díaz-Ruiz R, Satovic Z, Avila CM, Alfaro CM, Gutierrez MV, Torres AM, Román B: Confirmation of QTLs controlling Ascochyta fabae resistance in different generations of faba bean (Vicia faba L.). Crop Pasture Sci 2009, 60:353-361.

25. Díaz-Ruiz R, Torres A, Gutierrez MV, Rubiales D, Cubero Jl, Kharrat M, Satovic Z, Román B: Mapping of quantitative trait loci controlling Orobanche foetida Poir. resistance in faba bean (Vicia faba L.). African J Biotechnol 2009, 8:2718-2724.

26. Díaz R, Torres AM, Satovic Z, Gutierrez MV, Cubero Jl, Román B: Validation of QTLs for Orobanche crenata resistance in faba bean (Vicia faba L.) across environments and generations. Theor Appl Genet 2010, 120:909-919.

27. Truco MJ, Antonise R, Lavelle D, Ochoa O, Kozik A, Witsenboer H, Fort S, Jeuken MJW, Kesseli RV, Lindhout P, Michelmore RW: A high-density, integrated genetic linkage map of lettuce (Lactuca spp.). Theor Appl Genet 2007, 115:735-746.

28. Varshney RK, Marcel TC, Ramsay L, Russell J, Röder MS, Stein N, Waugh R, Langridge P, Niks RE, Graner A: A high density barley microsatellite consensus map with 775 SSR loci. Theor Appl Genet 2007, 114(6):1091-103.

29. Shirasawa K, Bertioli DJ, Varshney RK, Moretzsohn MC, Leal-Bertioli SC, Thudi M, Pandey MK, Rami JF, Foncéka D, Gowda MV, Qin H, Guo B, Hong Y, Liang X, Hirakawa $H$, Tabata S, Isobe S: Integrated consensus map of cultivated peanut and wild relatives reveals structures of the $A$ and $B$ genomes of Arachis and divergence of the legume genomes. DNA Res 2013, 20(2):173-184. doi:10.1093/dnares/dss042.

30. Somers JD, Isaac P, Edwards K: A high-density microsatellite consensus map for bread wheat (Triticum aestivum L.). Theor Appl Genet 2004, 109:1105-1114.

31. Davis GL, McMullen MD, Baysdorfer C, Musket T, Grant D, Staebell M, Xu G, Polacco M, Koster L, Melia-Hancock S, Houchins K, Chao S, Coe EH Jr: A maize map standard with sequenced core markers, grass genome reference points and 932 expressed sequence tagged sites (ESTs) in a 1736-locus map. Genetics 1999, 152:1137-1172.

32. Close TJ, Bhat PR, Lonardi S, Wu Y, Rostoks N, Ramsay L, Druka A, Stein N, Svensson JT, Wanamaker S, Bozdag S, Roose ML, Moscou MJ, Chao S, Varshney RK, Szucs P, Sato K, Hayes PM, Matthews DE, Kleinhofs A, Muehlbauer GJ, DeYoung J, Marshall DF, Madishetty K, Fenton RD, Condamine P, Graner A, Waugh R: Development and implementation of high-throughput SNP genotyping in barley. BMC Genomics 2009, 10:582.

33. Antonio BA, Inoue T, Kajiya H, Nagamura $Y$, Kurata N, Minobe $Y$, Yano M, Nakagahra M, Sasaki T: Comparison of genetic distance and order of DNA markers in five populations of rice. Genome 1996, 39:946-956.

34. Hwang T-Y, Sayama T, Takahashi M, Takada Y, Nakamoto Y, Funatsuki H, Hisano H, Sasamoto S, Sato S, Tabata S, Kono I, Hoshi M, Hanawa M, Yano C, Xia Z, Harada K, Kitamura K, Ishimoto M: High-density integrated linkage map based on SSR markers in soybean. DNA Res 2009, 16:213-225. doi:10.1093/dnares/dsp010.

35. Bordat A, Savois V, Nicolas M, Salse J, Chauveau A, Bourgeois M, Potier J, Houtin H, Rond C, Murat F: Translational genomics in legumes allowed placing in silico 5460 unigenes on the Pea functional Map and identified candidate genes in Pisum sativum L. G3-Genes genomes. Genetics 2011, 13(2):93-103.

36. Millan $T$, Winter $P$, Jüngling $R$, Gil J, Rubio J, Cho S, Cobos MJ, Iruela M, Rajesh PN, Tekeoglu M, Kahl G, Muehlbauer FJ: A consensus genetic map of chickpea (Cicer arietinum L.) based on 10 mapping populations. Euphytica 2010, 175:175-189.

37. Galeano CH, Fernandez AC, Franco N, Cichy K, McClean P, Vanderleyden J, Blair MW: Saturation of an intra-gene pool linkage map: towards a unified consensus linkage map for fine mapping and synteny analysis in common bean. PLoS One 2011, 6(12):e28135. doi:10.1371/journal.pone.0028135. 
38. Bohra A, Saxena RK, Gnanesh BN, Kulbhushan Saxena K, Byregowda M, Rathore A, KaviKishor PB, Cook DR, Varshney RK: An intra-specific consensus genetic map of pigeonpea [Cajanus cajan (L.) Millspaugh] derived from six mapping populations. Theor App/ Genet 2012, 125(6):1325-1338.

39. Muchero W, Diop NN, Bhat PR, Fenton RD, Wanamaker S, Pottorff M, Hearne S, Cisse N, Fatokun C, Ehlers JD, Roberts PA, Close TJ: A consensus genetic map of cowpea [Vigna unguiculata (L) Walp.] and synteny based on EST-derived SNPs. Proc Natl Acad Sci U S A 2009, 106:18159-18164.

40. Gautami B, Foncéka D, Pandey MK, Moretzsohn MC, Sujay V, Qin H, Hong Y, Faye I, Chen X, Prakash AB, Shah TM, Gowda MVC, Nigam SN, Liang X, Hoisington DA, Guo B, Bertioli DJ, Ram JF, Varshney RK: An international reference consensus genetic map with 897 marker loci based on 11 mapping populations for tetraploid groundnut (Arachis hypogaea L.). PLoS One 2012, 7(7):e41213. doi:10.1371/journal.pone.0041213. 2012.

41. Isobe S, Kölliker R, Hisano H, Sasamoto S, Wada T, Klimenko I, Okumura K, Tabata S: Construction of a consensus linkage map for red clover (Trifolium pratense L). BMC Plant Biol 2009, 9:57. doi:10.1186/1471-2229-9-57.

42. Wu Y, Close TJ, Lonardi S: Accurate construction of consensus genetic maps via integer linear programming. IEEE/ACM Trans. Comput Biol Bioinform 2011, 8:381-394. doi:10.1109/TCBB.2010.35.

43. Rajaram E, Nepolean T, Senthilvel S, Varshney RK, Vadez V, Srivastava RK, Shah TM, Supriya A, Kumar S, Kumari BR, Bhanuprakash A, Narasu ML, Riera-Lizarazu O, Hash CH: Pearl millet [Pennisetum glaucum (L.) R. Br.] consensus linkage map constructed using four RIL mapping populations and newly developed EST-SSRs. BMC Genomics 2013, 14:159. doi:10.1186/ 1471-2164-14-15

44. Wang J, Lydiate D, Parkin I, Falentin C, Delourme R, Carion P, King GJ: Integration of linkage maps for the Amphidiploid Brassica napus and comparative mapping with Arabidopsis and Brassica rapa. BMC Genomics 2011, 12:101.

45. Khan MA, Han Y, Zhao YF, Troggio M, Korban SS: A multi-population consensus genetic map reveals inconsistent marker order among maps likely attributed to structural variations in the apple genome. PLOS One 2012, 7(11):e47864. doi:10.1371/journal.pone.0047864.

46. Han Y, Zheng D, Vimolmangkang S, Khan MA, Beever JE, Korban SS: Integration of physical and genetic maps in apple confirms whole-genome and segmental duplications in the apple genome. J Exp Bot 2011, 62:5117-5130. doi:10.1093/jxb/err215.

47. Vezzulli S, Troggio M, Coppola G, Jermakow A, Cartwright D, Zharkikh A, Stefanini M, Grando MS, Viola R, Adam-Blondon AF, Thomas M, This P, Velasco R: A reference integrated map for cultivated grapevine (Vitis vinifera L.) from three crosses, based on 283 SSR and 501 SNP-based markers. Theor Appl Genet 2008, 117:499-511.

48. Mace ES, Rami J-F, Bouchet S, Klein P, Klein RR, Kilian A, Wenzl P, Xia L, Halloran $K$, Jordan DR: A consensus genetic map of sorghum that integrates multiple component maps and high-throughput diversity array technology (DArT) markers. BMC Plant Biol 2009, 9:13. doi:10.1186/14712229-9-13.

49. Spiller M, Linde M, Hibrand-Saint Oyant L, Tsai C-J, Byrne DH, Smulders MJ, Foucher F, Debener T: Towards a unified genetic map for diploid roses. Theor Appl Genet 2011, 122:489-500.

50. Marone D, Laido' G, Gadaleta A, Colasuonno P, Ficco DBM, Giancaspro A Giove S, Panio G, Russo MA, De Vita P, Cattivelli L, Papa R, Blanco A, Mastrangelo AM: A high-density consensus map of $A$ and $B$ wheat genomes. Theor Appl Genet 2012, 125:1619-1638. doi:10.1007/s00122-012-1939-y.

51. Ruiz-Rodriguez MD, Avila CM, Torres AM, Fuchs J, Schubert I: Anchoring of genetic linkage maps to the chromosome complement of Vicia faba $\mathrm{L}$. Mole breed. in press doi:10.1007/s11032-013-9969-y.

52. Kaló P, Choi HK, Ellis N, Kiss GB: Synteny and Comparative Genomics between Model and Cool Season Grain Legumes. In Genetics, Genomics and Breeding in Crop Plants: Cool Season Food Legumes. Edited by de la Vega P, Torres AM, Cubero Jl, Kole C. New Hampshire, Jersey, Plymouth: Science Pubs Inc; 2011:285-302

53. Choi HK, Mun JH, Kim DJ, Zhu H, Baek JM, Mudge J, Roe B, Ellis N, Doyle J, Kiss GB, Young ND, Cook DR: Estimating genome conservation between crop and model legume species. Proc Natl Acad Sci U S A 2004, 101:15289-15294

54. Kaló P, Seres A, Taylor SA, Jakab J, Kevei Z, Kereszt A, Endre G, Ellis THN, Kiss GB: Comparative mapping between Medicago sativa and Pisum sativum. Mol Genet Genom 2004, 272:235-246.
55. Zhu H, Choi HK, Cook DR, Shoemaker RC: Bridging model and crop legumes through comparative genomics. Plant Physiol 2005, 137:1189-1196.

56. Nelson MN, Phan HTT, Ellwood SR, Moolhuijzen PM, Hane J, Williams A, O'Lone CE, Fosu-Nyarko J, Scobie M, Cakir M, Jones MGK, Bellgard M, Ksiarkiewicz M, Wolko B, Barker SJ, Oliver RP, Cowling WA: The first gene-based map of Lupinus angustifolius L. -location of domestication genes and conserved synteny with Medicago truncatula. Theor Appl Genet 2006, 113:225-238

57. Phan HTT, Ellwood SR, Ford R, Thomas S, Oliver R: Differences in syntenic complexity between Medicago truncatula with Lens culinaris and Lupinus albus. Funct Plant Biol 2006, 33:775-782.

58. Nayak SN, Zhu HY, Varghese N: Integration of novel SSR and gene-based SNP marker loci in the chickpea genetic map and establishment of new anchor points with Medicago truncatula genome. Theor Appl Genet 2010, 120:1415-1441.

59. Marcel TC, Varshney RK, Barbieri M, Jafary H, Kock MJD, Graner A, Niks RE: A high-density consensus map of barley to compare the distribution of QTLs for partial resistance to Puccinia hordei and of defence gene homologues. Theor App/ Genet 2007, 114:487-500. doi:10.1007.

60. Cockram J, White J, Zuluaga DL, Smith D, Comadran J, Macaulay M, Luo Z, Kearsey MJ, Werner P, Harrap D, Tapsell C, Liu H, Hedley PE, Stein N, Schulte D, Steuernagel B, Marshall DF, Thomas WTB, Ramsay L, Mackay I, Balding DJ, Waugh R, O'Sullivan DM, The AGOUEB Consortium: Genome-wide association mapping to candidate polymorphism resolution in the unsequenced barley genome. Proc Natl Acad Sci U S A 2010, 107(50):21611-21616. doi:10.1073/pnas.1010179107.

61. Sehgal D, Rajaram V, Vadez V, Hash CT, Yadav RS: Integration of gene-based markers in pearl millet genetic map for identification of candidate genes underlying drought tolerance quantitative trait loci. BMC Plant Biol 2012, 12:9.

62. Swamy BP, Vikram P, Dixit S, Ahmed HU, Kumar A: Meta-analysis of grain yield QTL identified during agricultural drought in grasses showed consensus. BMC Genomics 2011, 2:319. doi:10.1186/1471-2164-12-319.

63. Muchero W, Ehlers JD, Close TJ, Roberts PA: Genic SNP markers and legume synteny reveal candidate genes underlying QTL for Macrophomina phaseolina resistance and maturity in cowpea [Vigna unguiculata (L) Walp.]. BMC Genomics 2011, 12:8.

64. Pottorff M, Ehlers JD, Christian Fatokun, JD, Philip AR, Timothy JC: Leaf morphology in Cowpea [Vigna unguiculata (L.) Walp]: QTL analysis, physical mapping and identifying a candidate gene using synteny with model legume species. BMC Genomics 2012, 13:234.

65. Chen X, Hedley PE, Morris J, Liu H, Niks RE, Waugh R: Combining genetical genomics and bulked segregant analysis-based differential expression: an approach to gene localization. Theor App Gen 2011, 122:1375-1383.

66. Madrid E, Palomino C, Plötner A, Horres R, Jüngling R, Rotter B, Winter P, Kahl G, Torres AM: DeepSuperSage analysis of the Vicia faba transcriptome in response to Ascochyta fabae infection. Phytopathologia Mediterranea 2013, 52(1):166-182.

67. Yang T, Bao S, Ford R, Jia T, Guan J, He Y, Sun X, Jiang J, Hao J, Zhang X, Zong $X$ : High-throughput novel microsatellite marker of faba bean via next generation sequencing. BMC Genomics 2012, 13:602.

68. Kaur S, Pembleton L, Cogan N, Savin K, Leonforte T, Paull J, Materne M, Forster J: Transcriptome sequencing of field pea and faba bean for discovery and validation of SSR genetic markers. BMC Genomics 2012, 13:104.

69. Cubero Jl: On the evolution of Vicia faba L. Theor App/ Genet 1974, 45:47-51.

70. Zeid M, Mitchell S, Link W, Carter M, Nawar A, Fulton T, Kresovich S: Simple sequence repeats (SSRs) in faba bean: new loci from Orobancheresistant cultivar 'Giza 402'. Plant Breeding 2009, 128:149-155.

71. Loridon K, McPhee K, Morin J, Dubreuil P, Pilet-Nayel ML, Aubert G, Rameau C, Baranger A, Coyne C, Lejeune-Henaut I, Burstin J: Microsatellite marker polymorphism and mapping in pea (Pisum sativum L.). Theor App/ Genet 2005, 111:1022-103.

72. Palomino C, Fernández-Romero MD, Rubio J, Torres A, Moreno MT, Millan T: Integration of new CAPS and dCAPS-RGA markers into a composite chickpea genetic map and their association with disease resistance. Theor Appl Genet 2009, 118:671-682.

73. Timmerman-Vaughan GM, Frew TJ, Weerden NF: Characterization and linkage mapping of R-gene analogous DNA sequences in pea (Pisum sativum L). Theor App/ Genet 2000, 101:241-247. 
74. Prioul-Gervais S, Deniot G, Receveur EM, Frankewitz A, Fourmann M, Rameau C, Pilet-Nayel ML, Baranger A: Candidate genes for quantitative resistance to Mycosphaerella pinodes in pea (Pisum sativum L.). Theor App Gen 2007, 114:971-984.

75. Michelmore RW, Paran I, Kesseli RV: Identification of markers linked to disease-resistance genes by bulked segregate analysis: A rapid method to detect markers in specific genomic regions by using segregating populations. Proc Natl Acad Sci U S A 1991, 88:9828-9832.

76. Lander ES, Green P, Abramson J, Barlow A, Dali MJ, Lincoln DE, Newburg L: MAPMAKER: an interactive computer program for constructing genetic linkage maps of experimental and natural populations. Genomics 1987, 1:174-181.

77. Wu Y, Bhat PR, Close TJ, Lonardi S: Efficient and accurate construction of genetic linkage maps from the minimum spanning tree of a graph. PLoS Genet 2008, 4:e1000212.

78. Kosambi DD: The estimation of map distance from recombination values. Ann Eugen 1944, 12:172-175.

79. Wang S, Basten CJ, Zeng ZB: Windows QTL Cartographer 2.5. Department of Statistics, North Carolina State University, Raleigh, NC. 2010. http://statgen.ncsu.edu/qtlcart/WQTLCart.htm.

80. Churchill GA, Doerge RW: Empirical threshold values for quantitative trait mapping. Genetics 1994, 138:963-971.

81. Yap IV, Schneider D, Kleinberg J, Matthews D, Cartinhour S, McCouch SR: A graph-theoretic approach to comparing and integrating genetic, physical and sequence-based maps. Genetics 2003, 165:2235-2247.

82. Muñoz-Amatriaín M, Moscou MJ, Bhat PR, Svensson JT, Bartoš J, Suchánková P, Šimková P, Endo TR, Fenton RD, Lonardi S, Castillo AM, Chao S, Cistué L, Cuesta-Marcos A, Forrest KL, Hayden MJ, Hayes PM, Horsley RD, Makoto K, Moody D, Sato D, Vallés MP, Wulff BBH, Muehlbauer GJ, Doležel J, Close TJ: An improved consensus linkage map of barley based on flow sorted chromosomes and SNP markers. The Plant Genome 2011, 4:238-249.

83. Voorrips RE: MapChart: software for the graphical presentation of linkage maps and QTLs. J Hered 2002, 93:7-78.

doi:10.1186/1471-2164-14-932

Cite this article as: Satovic et al: A reference consensus genetic map for molecular markers and economically important traits in faba bean (Vicia faba L.). BMC Genomics 2013 14:932.

\section{Submit your next manuscript to BioMed Central and take full advantage of:}

- Convenient online submission

- Thorough peer review

- No space constraints or color figure charges

- Immediate publication on acceptance

- Inclusion in PubMed, CAS, Scopus and Google Scholar

- Research which is freely available for redistribution 